\title{
A POLIFONIA DA SOCIOLOGIA NO ENSINO MÉDIO
}

HANDFAS, Anita; MAÇAIRA, Julia Podessa (Org.). Dilemas e perspectivas da sociologia na educação básica. Rio de Janeiro: E-papers, 2012, 324 p.

Apesar de ter uma história intermitente nos currículos escolares, cujo único período de estabilidade se deu entre os anos de 1925 a 1942, situado entre as reformas Rocha Vaz e Capanema, a sociologia vem retomando gradativamente seu espaço na escola desde os anos 1980, consolidando-se com o Parecer CNE/CEB n. 38/06 e com a Lei n. 11.684/08, que a reintroduzem em tornas as séries do ensino médio. Esse processo de retomada de espaço no currículo vem sendo acompanhado do incremento da produção acadêmica sobre a temática, substanciado em pesquisas desenvolvidas principalmente em nível de pós-graduação, cujos resultados são divulgados em dossiês temáticos em

Alguns espaços têm se destacado no processo de divulgação dos resultados das pesquisas envolvendo o ensino de sociologia. Chamaríamos a atenção para três: Grupo de Trabalho Ensino de Sociologia, cujas atividades ocorrem desde 2005 junto ao Congresso Brasileiro de Sociologia; o Encontro Nacional sobre o Ensino de Sociologia na Educação Básica, cuja primeira edição ocorreu em 2009; e o Congresso da Associação Brasileira de Ensino de Ciências Sociais, que ocorreu pela primeira vez em 2013 periódicos, coletâneas, grupos de trabalhos e eventos especializados. ${ }^{1}$ Contudo, a literatura a respeito ainda é tímida se comparada àquela produzida em torno do ensino de outras disciplinas escolares.

É nesse contexto que se insere a coletânea organizada por Anita Handfas e Julia Polessa Maçaira. Com 17 capítulos, a obra divide-se em três partes: Formação do Cientista Social; Currículo; e Livro Didático. Esta última ocupando um espaço mais restrito dentro da obra. Apresenta-se como um dos diferenciais a pluralidade de autores, entre os quais se encontram professores universitários, professores da educação básica, professores em formação e estudantes de pós-graduação.

Na primeira parte, é trazida uma interessante reflexão sobre o processo de formação inicial do professor de sociologia. No capítulo 
"Formação de professores de sociologia: um debate em aberto", Anita Handfas analisa os argumentos contrários e favoráveis aos diversos modelos de formação docente disponíveis. A autora destaca que, apesar de se tratar de um tema relevante para a formação de professores em todas as áreas, no caso da sociologia isso ganha ainda mais relevo, dada a profunda carência de professores com formação específica lecionando na educação básica e o curto tempo de institucionalização dessa ciência na escola. O texto começa por recuperar os argumentos legais em torno da formação de professores, afunilando para o caso específico da criação do curso de licenciatura de ciências sociais na Universidade Federal do Rio de Janeiro - UFRJ. A autora propõe uma guinada na discussão, saindo do plano institucional para o social, de modo a trazer novos elementos para a compreensão da formação docente.

Ana Lucia Lennert chama a atenção para os dados disponíveis no Censo da Educação que mostram a situação mais frágil do campo das ciências humanas, e da sociologia em particular, no currículo escolar. A autora destaca ainda os percursos traçados para se tornar professor de sociologia, indicando fatores como: a opção pelo curso a partir das vivências em diversos espaços de atuação política, social e cultural; a falta de clareza com relação ao curso ao entrar em contato com o mesmo; e a resistência inicial em aceitar a docência como um campo de atuação.

Viviane Gonzalez Dias ressalta as possibilidades pedagógicas abertas pela pesquisa partindo de sua própria experiência como professora, na qual teve a oportunidade de desenvolver com os alunos uma pesquisa em torno dos fatores que interferem no desempenho no ensino médio.

O que fica patente nesses dois capítulos é que a prática docente de sociologia no ensino médio é marcada pela pluralidade de possibilidades que se abrem desde a trajetória caudalosa dos professores até as questões abertas por meio da aplicação dos conhecimentos adquiridos ao longo da graduação em ciências sociais, que nesse caso inclui não apenas as contribuições teóricas do curso como também metodológicas.

Ana Beatriz Maia Neves e Camila Melo tocam em uma questão bastante relevante: o estágio supervisionado, compreendido como um rito de passagem importante para a formação docente. As autoras alertam para o fato de que não apenas o estagiário aprende com esse processo, como também o próprio professor envolvido, que consegue abrir canais de diálogo e de atualização teórica na área de ciências sociais. Já o trabalho de Carlos Eugenio Soares de Lemos, Glauber Rabelo Matias e Lidiane Rangel de Oliveira trata de uma experiência de estágio desenvolvida na Universidade para a Terceira Idade. Além das singularidades envolvendo o ensino de sociologia, abordam-se as especificidades do público envolvido e de como se pode pensar nas possibilidades de realizar uma aula de sociologia atraente para um público que traz outras questões e demandas para o espaço escolar. 
Nesses dois trabalhos encontra-se uma reflexão original sobre as vicissitudes do estágio na formação dos professores de sociologia que, longe de buscar apontar para fórmulas, traz questionamentos relevantes a serem considerados no campo formativo desses professores.

A segunda parte do livro é dedicada à questão do currículo de sociologia na educação básica. O texto de Rosana da Câmara Teixeira focaliza a relação entre o ensino de sociologia e a escolarização de jovens, indicando mesmo como possibilidade para o ensino dessa ciência a inclusão do tema culturas juvenis, como algo a ser trabalhado pelo professor. $\mathrm{O}$ texto de Amaury Cesar Moraes discute as concepções presentes nas Orientações Curriculares Nacionais da área de sociologia, das quais foi um dos elaboradores; e faz uma breve comparação entre as propostas contempladas pelos estados de São Paulo, Rio de Janeiro, Minas Gerais, Rio Grande do Sul e Paraná, apontando proximidades e diferenças quanto às temáticas exploradas e à forma como essas propostas curriculares são estruturadas.

Andréa Lúcia da Silva de Paiva, Giselli Avíncula Campos e Marcia Menezes Thomaz Pereira se voltam para a discussão em torno do currículo mínimo para a área de sociologia no Estado do Rio de Janeiro, aplicado em 2011, sobre como este se efetivou e quais foram as dificuldades encontradas no processo de implementação em cada série do ensino médio. O texto de Jefferson da Costa Soares, por sua vez, faz um recuo no tempo, remetendo às propostas de currículo de sociologia elaboradas por Delgado de Carvalho para o Colégio Pedro II que, em certa medida, se contrapunha à proposta elaborada pelo então Departamento Nacional de Ensino. Segundo o autor, Delgado de Carvalho estava preocupado em construir uma sociologia que não fosse normativa, mas sim criativa, voltada, inclusive, para a utilização de métodos de investigação como proposta pedagógica.

Lidiane Rangel e Oliveira e Marco Brandão analisam as tendências pedagógicas no ensino de sociologia com base em um estudo de caso. Consideram tanto a proposta pedagógica da escola investigada, que, segundo os autores, se fundamenta na pedagogia e Paulo Freire, como os elementos próprios do ensino de sociologia ali realizado. A conclusão a que chegam é que este ocorre de forma contextualizadora, não caindo no simples acúmulo de conceitos e teorias.

Fátima Ivone de Oliveira Ferreira e Silzane de Almeida Carneiro apresentam uma preocupação bastante pertinente para o ensino de sociologia, que remete à distinção entre o que é social e o que é propriamente sociológico, de modo a refletir sobre o processo de "superação" do senso comum enquanto ferramenta de explicação da realidade social. Nesse sentido, a sociologia passa a ser compreendida como disciplina que desloca o jovem do mundo individual e privado para o mundo público e que produz uma crítica à própria organização escolar. 
Alexandre Barbosa Fraga e Giselle Carino Lage, a partir de um caso empírico, voltam-se para uma das questões centrais ao ensino da sociologia, segundo as Orientações Curriculares Nacionais, que é a utilização da pesquisa articulada à pesquisa na educação básica - o que poderia, segundo os autores, tanto contribuir para a desconstrução de pré-noções acerca da realidade social quanto apontar para o aluno um sentido prático da sociologia.

Outra questão que ganha visibilidade na obra é o ensino dos autores clássicos, o que é abordado por José Colaço Dias Neto e Julia Polessa Maçaira. Mais que uma análise, os autores se propõem a elaborar sugestões didáticas para trabalhar com os clássicos no ensino médio, destacando a necessidade de contextualizá-los em seu tempo, assim como realizando uma interlocução contemporânea - o que é proposto reconhecendo os próprios desafios teóricos, metodológicos e institucionais dessa disciplina no atual cenário.

José Alexandre Oliveira Alves também se propõe a pensar o lugar dos clássicos no ensino de sociologia. Contudo, ele o faz a partir de uma pesquisa com professores fluminenses, classificando-os por fim em dois grupos. No primeiro não há menção aos clássicos nas aulas de sociologia. No segundo, essa referência é feita, contudo ele subdivide aqui em dois grupos: no primeiro há uma referência que ele chama de "transversal”, que seria aquela realizada de forma indireta, por meio dos temas trabalhados em sala de aula; o segundo apresentaria uma tendência “diretiva”, reservando um tempo especial para debater os clássicos dentro do programa da disciplina. Essas diversas práticas o autor relaciona com os diversos modelos curriculares, apontando claramente a necessidade de se afirmar a sociologia enquanto ciência na educação básica.

Tatiana Bukowitz traz à tona o debate sobre o lugar, ou melhor, a "serventia" como coloca a autora, da sociologia no contexto do capitalismo globalizado, optando por uma defesa do desenvolvimento de um olhar crítico, e mesmo engajado, o que fica posto nas entrelinhas, por parte do docente de sociologia, o que se encontra em consonância com o que é apregoado por vários docentes da educação básica, como inúmeras pesquisas têm demonstrado.

Na última parte, sobre livro didático, as análises recaem principalmente sobre os dois livros selecionados para a área de sociologia no Plano Nacional do Livro Didático: Tempos modernos, tempos de sociologia, coordenado por Helena Bomeny e Bianca Freire-Medeiros, e Sociologia para o ensino médio, de Nelson Tomazi, sendo também objeto de reflexão o livro Introdução à sociologia, de Pérsio de Oliveira. Há de se destacar que, no caso da sociologia, até mesmo pelo seu histórico no currículo escolar, ainda não há uma tradição consolidada na produção de livros didáticos, e que apenas em 2012 é que essa disciplina passa a constar do PNLD. Em todo o caso, as pesquisas têm apontado para a centralidade que esse recurso 
didático possui na prática docente dos professores, seja entre os que têm formação em ciências sociais, como também, e principalmente, entre aqueles que não têm formação na área, que representam hoje a maioria dos professores de sociologia atuando na Educação Básica no Brasil.

Fábio Braga do Desterro foca sua análise especificamente no tema das desigualdades nos livros acima citados, destacando tanto o lugar do ensino da sociologia, a estrutura de organização dos livros como os pontos fortes e fracos dos livros. O autor indica que, no primeiro livro analisado, há um enfoque especial sobre as desigualdades raciais e de gênero, havendo uma boa combinação de dados estatísticos e apresentação de interpretações sociológicas divergentes. Contudo, também é apontada a ausência da discussão sobre o conceito de mais-valia no capítulo sobre Marx. Quanto ao segundo livro citado, ele indica que há uma preferência na utilização de Marx para as análises mais concretas, de modo que Durkheim aparece como contraponto. No que tangencia às questões raciais e de gênero, no livro Sociologia para o Ensino Médio, o autor indica que essas questões encontram-se pouco exploradas, o que demandaria um esforço maior por parte dos docentes para trabalharem com elas em sala de aula.

A partir dos livros Sociologia para o ensino médio e Introdução à sociologia, Lidiane Rocha do Nascimento também centra sua análise em uma única categoria, no caso a de trabalho. Segundo a autora, o livro de Tomazi apresenta uma perspectiva mais relativista do conceito de trabalho, sendo em termos metodológicos mais plural, ao passo em que no livro de Oliveira a perspectiva de Marx estaria mais evidente. Em todo o caso, nos dois estariam ausentes os referenciais teóricos do pensamento social brasileiro sobre a questão do trabalho.

O que podemos perceber ao realizarmos um balanço geral dessa obra é que se trata de uma coletânea que avança em um duplo aspecto: tanto no sentido de pensarmos a produção de uma reflexão acadêmica sobre o ensino de sociologia, ainda que se deva ressaltar que os capítulos baseados em pesquisas empíricas não apresentam suficientemente os procedimentos metodológicos adotados; como no sentido de pensarmos uma produção que possa também subsidiar o professor de sociologia que atua na educação básica, além de ser um material indiscutivelmente relevante para se discutir nos cursos de formação de professores.

Certamente, a proliferação da produção acadêmica envolvendo o ensino de sociologia relaciona-se à própria dimensão institucional dessa disciplina na educação básica, e Dilemas e perspectivas da sociologia na educação básica reflete esse momento, que vem sendo acompanhado também pela expansão do número de cursos de licenciatura em ciências sociais, cujos modelos formativos precisam ser repensados considerando esse novo cenário. E o amadurecimento acadêmico da discussão é condição fundamental para tanto. 
O livro cumpre suas finalidades ao lançar múltiplos olhares sobre a realidade do ensino de sociologia, cujo campo de investigação ainda está se consolidando no Brasil. Todavia, chamaríamos a atenção para a necessidade de se desenvolver um diálogo mais intenso com a própria sociologia da educação, em especial com os autores que trabalham com sociologia do currículo, que poderiam trazer uma contribuição substancial para o debate, inclusive para produzir uma reflexão mais sistematizada sobre o lugar da sociologia no currículo escolar, que parece ser uma questão de fundo presente em quase todos os trabalhos, uma vez que os autores se confrontam tanto com as possibilidades abertas pela presença da sociologia na escola, e de que maneira operacionalizar tal feito, como também com os limites, principalmente institucionais, o que leva a obra a apresentar um tom bastante engajado, com conclusões consideravelmente convergentes quanto à importância da sociologia enquanto disciplina escolar, como não poderia deixar de ser, considerando os agentes que a produzem e o momento em que ela é produzida.

Reafirmamos aqui a relevância dessa coletânea polifônica, que certamente representa um avanço para a discussão sobre o ensino de sociologia, e de forma mais geral um avanço para o próprio campo da educação e das ciências sociais.

\author{
AMURABI OLIVEIRA \\ Professor doutor do Centro de Educação da \\ Universidade Federal de Alagoas - UFAL \\ amurabi_cs@hotmail.com
}

